\title{
The Portuguese Museums NETWORK
}

\section{Clara Camacho}

In the last three decades there has been a very significant rise in the number of museums in Portugal. This movement has followed international trends within the museum sector, but it has also assumed specific characteristics that are very much its own in relation to the profound political and institutional transformations which took place in the country following the institution of democracy on 25 April, 1974. Echoes of this major political event were felt throughout the whole of society and resulted in a greater involvement of local communities in the protection of heritage, which in turn led to the birth of a large number of museums.

\section{The current Portuguese museum SCENE}

From the second half of the 1970s the regeneration of Portuguese museums was clearly stimulated by, amongst other factors, greater contact with events taking place in museums abroad. It was also influenced by New Museology, particularly after the hosting of the International New Museology Workshop in Lisbon in 1985. Between the end of the 1970s and the mid 80s the changes occurring within Portuguese museology drew the attention of several internationally respected museologists, such as Per-Uno Agren (coordinator of the Unesco Mission in Portugal 1976 - 1979), GeorgesHenri Rivière (who worked with the Secretary of State for the Environment in a project to create ecomuseums in national parks in Portu- gal between 1978 and 79) and Hugues de Varine (Director of the Franco-Portugais Institute in Lisbon between 1983 and 84, who also took part in several local museum initiatives).

This new surge of ideas had begun back in 1976 when the Portuguese Government asked Unesco for specialist advice to help them resolve the main problems facing national museums. The Unesco mission consisted in visits to museums and workshops for their professional staff, at the end of which two final reports were produced containing a series of recommendations to the Portuguese Government. Although it was impossible to implement these recommendations at the time, their impact on the professional museum community was highly significant. Whilst this circulation of ideas had important repercussions for the transformation of the Portuguese museum sec- 
86 tor, it was the political front and the changes stemming from the institution of democracy that played a pivotal role. The growth in the number of new museums intensified, driven mainly by local government investment, attributable to the new framework of cultural democracy and the establishment of local and regional identities. Some of these new local museums have played a renovational role in shaping the museum panorama of today.

Alongside the rise in local museums, at the end of the 1970s and beginning of the 1980s, the central government created several national museums specialising in specific areas, such as the National Costume Museum, the National Theatre and the National Tile Museum.

In recent years private initiative has also played an important role in the creation of museums, in terms both of small local associations and large foundations. The latter have been directly related to important art collections, such as the internationally prestigious Gulbenkian Museum and the Serralves Museum of Contemporary Art.

In this brief introduction to Portuguese museums, one must also mention the role of universities. They have been educating museologists since the beginning of the 1990s, after an interruption of several years in the courses for museum curators. Since then this new generation of professionals has gradually been taking up jobs in museums; not yet in sufficient quantities to make up for all the existing deficiencies, but enough to represent a crucial factor for change in our museums.

For many years the situation we have just described failed to meet with a comprehensive response in terms of national museum policies. Nor were there any concerted national museum plans integrating different approaches and lines of action that would have allowed powers and jurisdictions between the different levels of administration to be clearly specified or that would have originated in a definition of the requirements needed for the creation of museums. The situation was characterised, therefore, by a great deal of initiative on the part of the different governing bodies (with particular emphasis on local government, but also private institutions), by the circulation of new ideas about museology and other relevant social changes. On the other hand, for a long time global intervention from the state was non-existent, in terms of action policies, or legislation and its application. This was in contrast to other countries that were developing systems for organisation and coordination between museums in which specific legislation for the museum sector or the accreditation of museums emerged as important instruments for the upgrading of this cultural area. Yet, Portugal failed to develop any national system of coordination or certification for its museums, during a period when elsewhere a movement for change was taking place which was unprecedented in the history of museology.

\section{Creation of the Portuguese Museums Network}

It was in this context that in 1991, under the Ministry of Culture, the Portuguese Museums Institute was created, on the presumption that the management of museums should be entrusted to an agency set up to deal with the specific problems in this sector. However, during the first years of this institute's existence, its work was almost exclusively with the national museums that came under its jurisdiction, whose difficult situation demanded a series of structural measures for their upgrading. It was only at the end of the 1990s, therefore, that the Por- 
tuguese Museums Institute was able to turn its attention to the museum sector in its entirety. Thus in 1997, the law governing the Portuguese Museums Institute outlined the proposal to create a Portuguese Museums Network to take immediate effect. This objective was also in line with the policy of the Ministry of Culture which had previously created a network for public libraries and a network for archives.

With the aim of acquiring a deeper knowledge of the situation in preparation for this new project, the Portuguese Museums Institute, in conjunction with the Cultural Activities Observatory (another agency under the Ministry of Culture), carried out a Survey of Portuguese museums. The study included 530 museums and was meant to provide a reliable profile of the country's museological reality. Among other aspects, the study was to highlight: the very recent establishment of most museums; the uneven geographical distribution, with massive concentration along the coast, particularly in the metropolitan areas of Lisbon and Porto, and a very sparse distribution in the interior; the large number of governing bodies, whether public or private; the heterogeneous nature of their collections. The survey also revealed the principle shortcomings and needs, identified by directors and those in charge of the museums which, in descending order, are the following: financial resources, staffing, premises, conservation, restoration, training, computer equipment, building maintenance, security and publicity.

The data from this survey are continually updated by way of an ongoing study carried out by the Cultural Activities Observatory. This provides us at any one moment with a diagnosis of the existing situation, such as the number of "self-designated museums" which at present exceeds eight hundred.
In 2000 having received the results of this survey, the Institute took the first concrete step towards setting up a Museums Network. It created a Project Structure, under its domain, with the principle aim of studying and drawing up a blueprint for such a network. In taking this measure, the Institute paved the way for a first global policy for the country's museums.

\section{ThreE STRUCTURAL AREAS: \\ TO INFORM, TRAIN AND UPGRADE}

At the end of the year 2000, beginning its work, the Project Structure team began by carrying out a programming study. This study was based on an examination of the historical process and the reality of Portuguese museums at the time, based on the data provided by the previously mentioned survey, within the context of international contemporary museology. This initial document was widely debated in meetings around the country. It resulted in a paper published in March 2001, Programming Lines for the Portuguese Museums Network (RPM Rede Portuguesa de Museus), which to date has served as the blueprint for our work.

Thus, the RPM is presented as a system of mediation and coordination for museums and kindred institutions, aimed at promoting communication and sharing between them, in order to bring about the upgrading of museums in Portugal. The wording expresses a concept of network with a broad spectrum of content, embracing two dimensions that complement one another: i.e. the dimension of "information network" and that of "physical network".

Taking this definition of "network", outlined above, and the results of the Museums Survey as the main points of reference, three main structural areas were defined for the Network: Information, Training and Upgrading. These 
88 areas have served as the anchor for specific programmes which were first developed on a regular basis from 2001 onwards.

The area of Information included two main channels of dissemination: the website (www.rpmuseus-pt.org) and the quarterly newsletter. There is no museology journal in Portugal and the only newsletters that exist belong to the Portuguese Association of Museology and the Portuguese National Commission of ICOM, written for their respective members. The interest prompted by the publication of the Network's website and newsletter, of which ten issues have already been published, is therefore understandable. Subjects covered have included the dissemination of the Project Structure action programme, as well as articles on museological issues and news related to activities promoted by museums which are part of the network. Other publications are planned within this area. These include a manual on museum programming, now in the final stages of completion, and the preparation of a revised version of data on Portuguese museums, as a continuation of the 1998 survey.

The area of Training was mapped out according to the needs outlined by museum professionals and the gaps that existed in relation to initiatives set up by other Portuguese entities. In reality, there has been no provision for ongoing training for museum professionals, the promotion of initiatives for training and skills development being extremely rare. In contrast to this is the growing role of universities offering academic training for postgraduate degrees in Museology. Given this scenario, the RPM began promoting a regular training programme. Between 2001 and 2003 twenty-four training courses have been organised, attended by around five hundred participants. Judging from the evaluations, this area has been extremely successful. Staying within this area, a documentation centre specialising in museology was recently opened to the public. It is designed to provide support for museum professionals, students and teachers.

In the area of Upgrading and the funding needed for this, the Museum Upgrading Support Programme was set up. This represents the Ministry for Culture's first funding programme directed to museums that are not dependent on the central administration. It is divided into four main areas: museum programming; research and the study of collections; preventive conservation; and communications initiatives. Within this programme, and since 2001, 64 museums have received funding for 235 projects, totalling more than a million and a half Euros. A Museum Specialist Services Programme was also set up to provide specialist consultation in some fields. Preventive conservation and museum architecture have so far proven to be the areas most sought after.

Much of the Portuguese Museums Network's daily activity is also taken up with the appraisal of funding applications to the Operational Cultural Programme for new museums or the renovation of existing museums. This is a European Community funding programme with specific applications in the area of culture, run by the Ministry for Culture. It is the job of the Project Structure to complete the technical report on the museological significance of these applications, which also provides it with extensive practical knowledge concerning the development of the museum panorama. 
Membership of the Portuguese Museums Network: system of PRE-ACCREDITATION

Throughout the whole process of the gradual construction of the RPM special importance has been attributed to the voluntary membership of museums. This is based on a set of criteria based on the major pillars which define the condition of a museum, adapted to the scale or size of the museum in question and applicable to the whole museum sector. As we know, many of the entities calling themselves museums do not fulfil the criteria that this institution is committed to, although the concept of museum, as defined internationally by ICOM, varies from country to country. In our case, we chose from the very beginning, to adopt ICOM's definition in the process of determining membership of the RPM, using it as a reference for the appraisal of applications.

The fundamental objective in appraising these proposals has consisted in verifying that the candidates conform to the above-mentioned definition. In other words that they essentially reflect and perform their functions according to the definition and that they fulfill their respective social roles. In the initial stage, the process was aimed at establishing and consolidating the RPM and its action programmes. At the same time the intention has been to test out the system of accreditation that will be incorporated into the future Museums Law. Without the prior existence of support and coordination structures between museums it would be premature to initiate a programme of accreditation that was not accompanied by a global policy for the museum sector, in accordance with the areas already mentioned.

Based on these presuppositions, the following aspects are considered to be crucial for the pro- cess of membership in the Network and to correspond to the overall criteria expected of the respective candidacies: a) commitment to the museum's social function; b) observation of the need to preserve and enhance collections and reserves; c) conditions of sustainability.

As regards commitment to the social function of the museum, the intention is to ascertain clearly and in detail how the museum defines its objectives and its mission. There should be a clear correspondence between these objectives and the way the museum operates, its plan of activities and regular initiatives to publicise its activities, as well as its connection to the community and the target public that it serves.

As regards exercising care in the preservation and enhancement of its collections, the museum should demonstrate a knowledge of the collections in its keeping in terms of source, origins and identification. Equally, there should be evidence of a commitment to the essential museological functions: research, conservation, documentation, communication and education, specifying in each case the conditions available for this to be effected. The museum must provide an inventory of its collection, show that it has taken the necessary measures for its conservation and security and possesses adequate premises to achieve this.

As regards sustainability, the museum must have a sufficient number of staff to properly fulfil its functions. Ideally, this resource should be inscribed within the museum's own statutes or that of its governing body. Equally, the budget or allocation of funds should be sufficient to cover its operational requirements and in proportion to the extent of its activities, its mission and its objectives.

The process of joining the RPM began in April 2001. It is open to all types of museums, regardless of their governing bodies, the sub- 
90 ject matter of their collections or their territorial constituency. The documentation that applicants are required to complete assumes a degree of study and self-reflection on the performance of the respective museum, backed up by meetings, contacts and visits by the Project Structure team.

\section{The museums within the Network}

The system began with an initial group of 28 museums under the tutelage of the Portuguese Museums Institute, to which were gradually added those museums which applied to join the Network, in accordance with the requirements laid down. It now consists of $114 \mathrm{mu}-$ seums. The situation so far, already very significant, allows us to make a summary analysis and description which, whilst referring to a micro-universe of museums, represents an important instrument for helping to define policies for the whole sector.

As regards administrative dependency, the museums within the Network are overwhelmingly public museums, amongst which those dependent on local government predominate (42\%). Amongst those accountable to central government $(30 \%)$, the most significant are the 28 museums governed by the Portuguese $\mathrm{Mu}$ seums Institute. These include national museums such as the National Museum of Ancient Art, the National Museum of Archaeology, the National Museum of Ethnology and the National Coach Museum. The number of museums dependent on other ministries is still small. For the moment there are two university museums and one museum accountable to the Ministry of Defence.

Of museums dependent on a regional administration there are 14 which are governed by the Regional Cultural Departments of the
Autonomous Regions of the Azores and Madeira. The signing of joint protocols between the Portuguese Museums Institute and the Governments of these Atlantic archipelagos has meant that, from its genesis, the RPM has included the island territories.

Given the historic context initially described, it is easy to explain the predominance of municipal museums within the Network. This corresponds to the current reality of the museum sector and reflects their initiative in preparing applications. They represent a diverse range of museums and collections, which include museums connected to the district such as the Seixal Ecomuseum and the Museum of Mértola; museums with special themes such as the Pottery Museum, the Labour Museum, the Stone Museum and the Paper Museum; art museums such as the Amadeo Sousa Cardoso Municipal Museum and archaeological museums such as the Vila Real Museum of Archaeology and Numismatics. However, museums with mixed collections predominate, especially in relation to archaeology, ethnography and art, with the growing role of industrial heritage also visible, as indicated by e.g. the Portimão Municipal Museum and the Gunpowder Museum.

As regards the geographical distribution, the museums are located predominantly in the north of the country (32\%), followed by Lisbon $(27 \%)$. This situation differs slightly from the distribution of museums in the country as a whole, where the region around the capital has the highest concentration of museums, followed by the north. The distribution of the remainder of the museums corresponds to the overall distribution of museums throughout Portugal, as well as the present demographic distribution in the country, which is mainly concentrated along the coast.

In relation to collections held by these mu- 
seums, there is a predominance of art collections (30\%), followed by ethnographic (11\%), archaeological (9\%) and historical collections (7\%). Museums of science and technology are rare $(5 \%)$, reflecting the interest of the Portuguese museums in this field.

Regarding the age of the museums in the Network, it should be stressed that just over half of the museums were founded after 1974 (57\%), with 29 founded during the last ten years, which confirms the relatively recent establishment of Portuguese museums.

In this very brief description of the museums that currently make up the RPM, it is also important to mention some of the problems that have beset them. These problems have resulted in the planning and implementation of certain measures, and recommendations to the respective governing bodies and their supervision. The main problems encountered amongst the Network's museums have been related, above all, to their statutes and management, particularly in terms of lack of qualified staff, which has affected the carrying out of museological functions, especially concerning documentation and conservation.

\section{Appraisal AND perspectives for CONTINUITY}

In defining the conceptual grid and programming lines for the RPM it seemed to us essential that this project should be able to fill a "gap" that has existed for many years in Portuguese museology. This was the result of omissions both in terms of the regulation of existing museums and the existence of any programmes to coordinate and support them. Yet, it seemed to us that given the wide field of action open to us and the present state of the sector, it would be more appropriate and more efficient from a strategic point of view, to begin by carrying out a coherent programme of intervention based on the three main areas already referred to (Information, Training, Upgrading). At the same time, we would begin the construction of the Portuguese Museums Network itself through the process of open and voluntary membership for museums. Only after fulfilling and testing these stages would it be opportune to proceed with the preparation of a new legislative framework which could benefit from the experience acquired during these three years of work.

Approval of membership of the RPM has, in our opinion, contributed to the upgrading of museums not only directly through the technical and financial support, but also by helping to create a greater awareness on the part of the respective governing bodies about making available the resources for this upgrading. The influence of the RPM is, therefore, clearly seen in the clear statutory insertion of the museums within the governing body required and motivated by RPM. This has had repercussions in the management of museums and in the appropriate allocation of human and financial resources for operations and the total fulfilment of all museological functions. These aspects are contained within the recommendations made in the evaluation report for museums applying for membership, compliance with which is assessed after one year's membership.

The results of some of the RPM requirements are also evident regarding the upgrading of museum staff. This is particularly true with regard to incentives for training, seen for example in the frequency of training programmes already mentioned, as well as in the use of staff specialised in different areas of museum work. Alongside the contribution made by the RPM's specific support programmes (techni- 
92 cal and financial support) for the realisation of various upgrading projects for museums, the publicising of the museums' activities and lines of work through the Newsletter and the Site has shown increasingly encouraging results amongst museums and their professionals.

Given their characteristics, it is hoped that the RPM museums can strengthen and develop their work and serve as examples of good practice for other museum-related initiatives. In this sense, one of the main objectives has been fulfilled in that the RPM has been constructed with respect to the intrinsic diversity of museum practices, it has identified and addressed failings and it has been exigent in relation to statutory and functional limitations.

As already mentioned, instead of taking legislation as a starting point, the strategy we adopted was to view the formulation of specific legislation and regulations for the museum sector as the desirable end result of a process. On this basis, the first draft of a law for Portuguese museums was recently prepared, on the initiative of the Portuguese Museums Institute, and with the support of a Working Group of museum professionals, including representatives of the National Commission of ICOM and the Portuguese Association of Museology. The RPM Project Structure was fully involved with this work.

This comprehensive proposal will establish a legal framework for the museum sector. It starts with a definition of the concept of museum, resulting from the work of the abovementioned group. This serves as the basis for the identification of museum functions and the regulation of a series of responsibilities associated with their fulfilment. At a time when the concept of museum is being widely debated internationally, this Portuguese proposal will certainly make a contribution to the issue.
The draft law establishes the procedure that must be followed for the creation of new museums; it determines the need for trained personnel, as well as the financial resources appropriate for the sustainability of the museum, it establishes a model of accreditation for museums, and lays down decentralised forms of technical support; it institutionalises the Portuguese Museums Network and creates a new consultative agency under the direct control of the Ministry of Culture.

It is a text which reinforces the responsibilities of the state and private entities which own museums, just as it reinforces the responsibilities of the specialist teams who work within them, in a common search for new standards. The participatory manner by which this paper was drawn up, the expectation and interest that its realisation has prompted and the wide consensus concerning the majority of its articles, clearly point to the urgency of approving this ground-breaking bill for the Portuguese museum sector. At present, and following the approval of the Portuguese government, the proposal will go before the parliament.

Since 2000, the work of the Project Structure has developed as a constant union between the need for prerequisites, from which parameters and quality standards for museums emanate and the need for action, inherent within a policy of coordination and support and which contains the instruments needed to attain the desired standards. This project constitutes an initial stage in a long journey which museums and agencies working in the area of museology must make together in order to improve the care of the country's heritage in their guardianship and to improve their role in society.

Clara Camacho is coordinator of the RPM e-mail: coordenadora@rpmuseus-pt.org 